\title{
Anxiety during COVID-19 Pandemic among Students of University of Shkoder, Albania
}

\author{
E. Hasmujaj and V. Dizdari
}

\section{ABSTRACT}

The main purpose of the present study is to investigate the extent of anxiety symptoms during the COVID-19 pandemic on university students of Shkoder. Another purpose is to find out the relationship between anxiety symptoms with some demographical variables such as gender, age, level of study, field of study and having been infected or not by coronavirus. Data was collected using the Corona Disease Anxiety Scale (CDAS), administered online to assess the anxiety level. The sample consists of 175 university students from different Faculties of the University of Shkoder. The results showed that the prevalence rate of heavy anxiety during the pandemic is about $10.3 \%$. T-test indicated that female students are more prone to experience anxiety during the pandemic than male ones. Anova analysis indicated that midwifery students show the highest level of anxiety compared to other fields of studies. But anxiety was not associated with age, level of study or having been infected by coronavirus. These findings are important in detecting the psychological consequences of the Covid-19 pandemic in different societies.

Keywords: Anxiety, CDAS, Covid-19, Students.
Published Online: November 17, 2021 ISSN: $2736-5522$

DOI: 10.24018 / ejsocial.2021.1.6.157

\section{E. Hasmujaj*}

Department of Psychology and Social Work, University of Shkoder, Albania. (e-mail: elona.hasmujaj@ ${ }^{@}$ unishk.edu.al) V. Dizdari

Department of Psychology and Social Work, University of Shkoder, Albania. (e-mail: visar.dizdari@ unishk.edu.al)

*Corresponding Author

\section{INTRODUCTION}

The Coronavirus disease 2019 (COVID-19) pandemic has emerged as a significant and global public health crisis affecting 192 countries, with about 183.000 .000 cases and more than 3.900 .000 confirmed deaths to July 2021 (John Hopkins Coronavirus Resource Center).

Major focus areas regarding the COVID-19 pandemic have been concentrated on physical health; however, the coronavirus pandemic has also an adverse impact on mental health (Fiorillo \& Gorwood, 2020). Elevated psychological distress related to the COVID-19 pandemic has been evidenced worldwide, including depression, anxiety and health anxiety (Lee, 2020; Rajkumar, 2020; González-Sanguino et al., 2020; Mazza et al., 2020; Taylor et al., 2020).

While young adults and students are less likely to be hospitalized of COVID-19 (Bialek et al., 2020), they have been identified as a vulnerable group, reporting elevated psychological distress and higher anxiety levels associated with the COVID-19 pandemic (Shah et al., 2021; Lei et al. 2020; Huang \& Zhao 2020). The anxiety is associated with three or more of the following symptoms for at least six months: restlessness, feeling keyed up or on edge, being easily fatigued, difficulty in concentrating or mind going blank, irritability, muscle tension, sleep disturbance, and irritability (Munir et al., 2019; Adwas et al., 2019).

Studies about psychological distress related to the coronavirus pandemic in Albania, especially among young adults and students are limited, so we conducted this study whose main purpose is to explore the prevalence of anxiety during the COVID-19 pandemic among university students of Shkoder. According to existing literature and recent findings in other countries, we examined if gender and having been infected by coronavirus are risk factors for ongoing anxiety related to COVID-19 (González-Sanguino et al., 2020; Mazza et al., 2020). We also tried to find out if there are other differences related to age, level and field of study in anxiety.

The findings from the current study can be used by other researchers and psychological professionals to develop appropriate interventions and inform future research to reduce anxiety and other psychological problems among university students during the COVID-19 pandemic.

Based on the review of the existing literature, the researcher addressed the following research questions, which will guide this study;

1. What is the prevalence of anxiety during the COVID-19 pandemic among students of the University of Shkoder?

2. Are there differences in the rates of anxiety during the COVID-19 pandemic in relation to gender, age, level and field of study?

3. Are there differences between students that have been infected or not by coronavirus in the rates of anxiety during the COVID-19 pandemic? 


\section{METHODS}

\section{A. Design}

This study used a cross-sectional design aimed to assess the prevalence of anxiety during pandemic Covid-19 among university students. Data was collected on the whole study population at a single point in time. That relies heavily on statistical techniques and mathematical numerical data, in order to answer to the research questions.

\section{B. Participants and Procedure}

The population of this study includes students from the University of Shkoder, Albania. It was created a purposive, non-probability sample of 175 subjects, where $n=158(90.3 \%)$ are female and $n=17(9.7 \%)$ are male, ranged in age from 18 to over 26 years old, with a mean age of \pm 20.8 .

The more detailed distribution of demographic findings can be seen in Table I. We invited students via e-mail to complete the online questionnaire (in google forms), informing them about the aims of the study and ethical guidelines for research through an informed consent form.

\section{Assessment Tools}

\section{a) Demographic Questions}

Participants were given at the beginning of the questionnaire some demographic questions which included standard categories such as gender, age, level of study, field of study and if they have been infected or not by coronavirus.

\section{b) Corona Disease Anxiety Scale (CDAS)}

CDAS is created by Alipour, Ghadami, Farsham and Dorri (2020). This questionnaire included 18 items and 2 factors; items 1 to 9 measure the physical symptoms, and items 10 to 18 measure the psychological symptoms (Alipour et al., 2020).

Each answer is scored based on a Likert scale from 0 to 3 . The marking for this questionnaire ranges from 0 to 54, the higher the marks are the greater the level of anxiety is. In this study, Cronbach's alpha score for this scale was estimated 0.92 .

\section{Data Analysis}

Data were analyzed using SPSS version 23.0 software (SPSS Inc., Chicago, IL), using reliability analysis, descriptive statistics, independent sample t-test and one-way Anova.

\section{Results}

\section{A. Distribution of Demographic Characteristics}

\begin{tabular}{cccc}
\multicolumn{2}{c}{ TABLE I: DEMOGRAPHIC CHARACTERISTICS OF THE RESPONDENTS } \\
\hline \hline Variables & Groups & Frequency & Percent \\
\hline \multirow{2}{*}{ Gender } & Female & 158 & $90.3 \%$ \\
& Male & 17 & $9.7 \%$ \\
\hline \multirow{5}{*}{ Age group } & $18-19$ & 59 & $33.7 \%$ \\
& $20-21$ & 71 & $40.6 \%$ \\
& $22-23$ & 26 & $14.9 \%$ \\
& $24-25$ & 8 & $4.6 \%$ \\
& +26 & 11 & $6.3 \%$ \\
\hline \multirow{5}{*}{ Level of study } & First-year & 68 & $38.9 \%$ \\
& Second-year & 52 & $29.7 \%$ \\
& Third-year & 24 & $13.7 \%$ \\
& Fourth-year & 25 & $14.3 \%$ \\
& Fifth-year & 6 & $3.4 \%$ \\
\hline \multirow{5}{*}{ Field of study } & Psychology & 44 & $25.7 \%$ \\
& Social Work & 63 & $35.4 \%$ \\
& Nursery & 22 & $12.6 \%$ \\
& Midwifery & 6 & $3.4 \%$ \\
& Economics & 40 & $22.9 \%$ \\
\hline \hline & Yes & 35 & $20 \%$ \\
& No & 90 & $51.4 \%$ \\
& I don't know & 50 & $28.6 \%$ \\
\hline
\end{tabular}

Table I shows the demographic characteristics of the sample. These findings suggest that 158 participants $(90.3 \%)$ were female and 17 participants $(9.7 \%)$ were male. In terms of age, 59 participants $(33.7 \%)$ were in the age range of 18-25 years, $71(40.6 \%)$ were aged $20-21,26(14.9 \%)$ were aged $22-23 ; 8(4.6 \%)$ were in the age range of 24-25 years and $11(6.3 \%)$ were over 26 years old. In terms of the level of study, 68 
participants (38.9\%) are first-year students, 52 participants $(29.7 \%)$ are second-year students, $24(13.7 \%)$ third-year students, 25 (14.3\%) fourth-year students, and 6 students (3.4\%) fifth-year students. 44 participants (25.7\%) are students of Psychology; 63 (35.4\%) of Social Work; 22 (12.6\%) of Nursery; 6 $(3.4 \%)$ of Midwifery and $40(22.9 \%)$ of Economics. To the question if they have been infected by coronavirus, 35 participants (20\%) answered "Yes", 90 participants (51.4\%) answered "No" and 50 participants $(28.6 \%)$ answered "I don't know."

\section{B. The Prevalence of Anxiety during Pandemic}

As shown in Table II of our 175 participants $75.4 \%$ had low anxiety $(n=132), 14.3 \%$ had moderate anxiety $(n=25)$ and $10.3 \%$ of the respondents had a potentially concerning level of anxiety $(n=18)$. Mean score of anxiety variable is $\mathrm{M}=13.10$ and the standard deviation $\mathrm{SD}=9.85$.

\begin{tabular}{ccccccc}
\multicolumn{6}{l}{ TABLE II: DESCRIPTIVE STATISTICS (FREQUENCY, PERCENTAGE, MEAN, STANDARD DEVIATION) OF ANXIETY } \\
\hline \hline Variable & Groups & Frequency & Percentage (\%) & Mean & S. Deviation & Total \\
\hline \multirow{4}{*}{ Anxiety } & Low level & 132 & 75.4 & & & \\
& Middle level & 25 & 14.3 & 13.10 & 9.85 & 175 \\
& High level & 18 & 10.3 & & & \\
\hline \hline
\end{tabular}

\section{Gender Differences in Anxiety}

We used independent samples t-test to examine gender differences in anxiety levels.

Homogeneity of variance according to Levene's test was statistically non-significant, which enabled further analysis $(\mathrm{p}=0.199>0.05)$. The mean value of anxiety in female students $(\mathrm{M}=13.72, \mathrm{SD}=9.91)$ is greater than in male ones $(M=7.29, \mathrm{SD}=7.15)$, the results are statistically significant, so we can see gender differences in anxiety $[\mathrm{t}(173)=2.598, \mathrm{p}=0.010<0.05]$, we can see also differences according to physical symptoms in anxiety level $[\mathrm{t}(173)=3.123, \mathrm{p}=0.002<0.05]$, where the mean value in female students $(M=10.46, S D=6.22)$ is greater than in male students $(M=5.59, S D=5.04)$, but there is no differences in terms of psychological symptoms related to anxiety [ $\mathrm{t}(173)=1.327, \mathrm{p}=0.186>0.05$ ]

\begin{tabular}{|c|c|c|c|c|c|c|c|}
\hline Variable & Gender variable & $\overline{\mathrm{N}}$ & Mean & S. Deviation & $\mathrm{t}(173)$ & F & $\mathrm{P}$ \\
\hline \multirow[t]{2}{*}{ Anxiety } & Female & 158 & 13.72 & 9.91 & \multirow{2}{*}{2.598} & \multirow{2}{*}{1.662} & \multirow{2}{*}{0.010} \\
\hline & Male & 17 & 7.29 & 7.15 & & & \\
\hline \multirow[t]{2}{*}{ Physical symptoms } & Female & 158 & 10.46 & 6.22 & \multirow{2}{*}{3.123} & \multirow{2}{*}{0.599} & \multirow{2}{*}{0.002} \\
\hline & Male & 17 & 5.59 & 5.04 & & & \\
\hline \multirow[t]{2}{*}{ Psychological symptoms } & Female & 158 & 3.26 & 4.75 & \multirow{2}{*}{1.327} & \multirow{2}{*}{3.254} & \multirow{2}{*}{0.186} \\
\hline & Male & 17 & 1.71 & 2.47 & & & \\
\hline
\end{tabular}

\section{Age Group Differences in Anxiety}

For a comparison of more than two group means, we used one-way analysis of variance (ANOVA). Homogeneity of variance according to Levene's test was statistically non-significant $(\mathrm{p}=0.755>0.05)$.

As can be seen from the Table IV, the mean score of anxiety is higher in 24-25 age group ( $M=18.50$, $\mathrm{SD}=12.81)$, but the results are statistically non-significant $[\mathrm{F}(4,170)=1.078, \mathrm{p}=0.369>0.05]$.

\begin{tabular}{cccccc} 
TABLE IV: MEAN, STANDARD DEVIATION, F AND P FOR DIFFERENT AGES ON ANXIETY \\
\hline \hline Groups & $\mathrm{N}$ & Mean & S. Deviation & $\mathrm{F}(4,170)$ & $\mathrm{p}$ \\
\hline $18-19$ & 59 & 11.66 & 8.28 & & \\
$20-21$ & 71 & 13.49 & 10.96 & & \\
$22-23$ & 26 & 12.73 & 8.91 & 1.078 & 0.369 \\
$24-25$ & 8 & 18.50 & 12.81 & & \\
+26 & 11 & 15.18 & 9.64 & & \\
\hline \hline
\end{tabular}

\section{E. Level and Field of Study in Anxiety}

As reported in Table V, ANOVA showed that there is no statistically significant difference between groups $\mathrm{F}[(4,170)=2.189, \mathrm{p}=0.072>0.05]$. These findings show that there is no difference in level of anxiety among students of different years of study.

\begin{tabular}{cccccc}
\multicolumn{6}{c}{ TABLE V: MEAN, STANDARD DEVIATION, F AND P FOR LEVEL OF STUDY ON ANXIETY } \\
\hline \hline Groups & $\mathrm{N}$ & Mean & S. Deviation & $\mathrm{F}(4,170)$ & $\mathrm{p}$ \\
\hline First & 68 & 13.13 & 11.27 & & \\
Second & 52 & 12.48 & 8.84 & & \\
Third & 24 & 10.62 & 5.89 & 2.189 & 0.072 \\
Fourth & 25 & 17.76 & 10.27 & & \\
Fifth & 6 & 8.87 & 7.08 & & \\
\hline \hline
\end{tabular}


Regarding to the field of study, as can be seen from the Table VI, the results are statistically significant $[F(4,170)=2.743, p=0.030<0.05]$. Homogeneity of variance according to Levene's test was statistically non-significant even in this case $(\mathrm{p}=0.708>0.05)$, so the mean score of anxiety is higher in midwifery students $(\mathrm{M}=24.67, \mathrm{SD}=9.66)$ followed by nursery students $(\mathrm{M}=14.05, \mathrm{SD}=10.02)$ and the lowest anxiety level is reported by economics students $(\mathrm{M}=10.87, \mathrm{SD}=9.15)$.

\begin{tabular}{ccccccc}
\multicolumn{6}{c}{ TABLE VI: MEAN, STANDARD DEVIATION, F AND T FOR ACADEMIC DisCIPLINE IN ANXIETY } & \\
\hline \hline Variable & Field of study & $\mathrm{N}$ & Mean & S. Deviation & F (4, 170) & $\mathrm{p}$ \\
\hline & Psychology & 44 & 13.29 & 11.59 & & \\
& Social Work & 63 & 12.93 & 8.27 & & \\
Anxiety & Nursery & 22 & 14.05 & 10.02 & 2.743 & 0.030 \\
& Midwifery & 6 & 24.67 & 9.66 & & \\
\hline \hline
\end{tabular}

\section{F. Having been Infected or not by Coronavirus in Anxiety}

Regarding to the question if they have been infected by coronavirus, Table VII shows that the results are statistically non-significant $[\mathrm{F}(2,172)=2.243, \mathrm{p}=0.784>0.05]$. Although the mean score of students that have been infected by coronavirus is higher $(\mathrm{M}=13.91, \mathrm{SD}=9.08)$ compared to other groups, the results have not statistical value. Homogeneity of variance according to Levene's test was statistically nonsignificant even in this case $(\mathrm{p}=0.977>0.05)$.

TABLE VII: MEAN, STANDARD DEVIATION, F AND P FOR BEING INFECTED OR NOT BY CORONAVIRUS IN ANXIETY LEVEL

\begin{tabular}{ccccccc}
\hline \hline Variable & Infected & $\mathrm{N}$ & Mean & S. Deviation & F (4,170) & $\mathrm{p}$ \\
\hline \multirow{4}{*}{ Anxiety } & Yes & 35 & 13.91 & 9.08 & & \\
& No & 90 & 12.62 & 10.30 & 2.243 & 0.784 \\
& I don't know & 50 & 13.38 & 9.69 & & \\
\hline \hline
\end{tabular}

\section{DISCUSSION}

This study was one of the first to measure psychological symptoms as a result of COVID-19 pandemic in a sample of university students in Albania. The results suggest that $24.6 \%$ of total number of participants reported moderate to high levels of anxiety symptoms. Similar to the current results, a study conducted with university students in China found that $25 \%$ of the participants experienced anxiety about finances and academic delays following the COVID-19 outbreak (Cao et al., 2020; Kibbey et al., 2021). The prevalence of higher levels of anxiety in this study is about 10.3\%, in the same line Al Salman et al. (2020) examined secondary school students during the academic year 2018-2019 and reported around 10\% of severe anxiety.

Our findings indicated that female students show higher level of anxiety than male students, which is consistent with results of recent studies (Kibbey et al., 2021; Lai et al., 2020), and might be understood considering the well-documented sex difference in affective disorders (McLean et al., 2011; Kibbey et al., 2021). But contradictory with the present study are the results of previous research of the authors who showed that there were no gender differences in anxiety among students of the Psychology and Social Work Department, University of Shkoder (Hasmujaj, 2021).

The findings of this study showed that there is no age differences in terms of anxiety during the pandemic, but contradictory with the present study are the results of other authors who showed that aging is a risk factor for developing various forms of emotional distress during the COVID-19 pandemic (Ahmed et al., 2020; Huang \& Zhao, 2020). Also, according to our findings, level of study was not related to anxiety. It was reported the same result in a study conducted to determine the predictors of anxiety during the COVID19 pandemic in Poland (Malesza \& Kaczmarek, 2020). Earlier studies on different topics reported mixed findings on differences in risk perceptions according to level of study (Bratt et al., 2000; Erblich et al., 2000; Malesza \& Kaczmarek, 2020).

There were higher mean levels of anxiety in midwifery students followed by nursery students. A survey by the Royal College of Midwives (RCM) shows over half (57\%) of midwives, maternity support workers (MSWs) and student midwives feel the current crisis has had a negative impact on their mental health ${ }^{1}$. Also a quantitative study carried out with nursing students during the COVID-19 pandemic has found high levels of anxiety (Savitsky et al.,2020). This result suggests that people who are more in contact with the disease can be at risk of having higher level of anxiety. According to the final finding: the mean score of students in our sample that have been infected by coronavirus is higher compared to other groups, but the difference is not statistically significant. Accordingly, anxiety increase is often seen in groups who discern high infection risk, and the study of Kef (2021) showed that it also correlates highly with having a symptom.

\footnotetext{
${ }^{1}$ https://www.rcm.org.uk/media-releases/2020/may/midwives-mental-health-hit-by-pandemic/.
} 
European Journal of Humanities and Social Sciences www.ej-social.org

\section{A. Limitations of the Study}

First, this study was conducted using non-probabilistic sampling techniques, which limits generalisation for the entire university. Second, the data were collected using an online self-administered questionnaire and there is a risk that participants did not take the compilation seriously.

\section{CONCLUSION AND RECOMMENDATIONS}

This study revealed that $75.4 \%$ of the university students reported low levels of anxiety related to the COVID-19 pandemic, $14.3 \%$ of them mild levels of anxiety and the prevalence of higher levels of anxiety is about $10.3 \%$. A sex difference was found, with female students presenting higher levels of anxiety. There were no statistically significant differences regarding to the level of study, age and being infected or not by coronavirus. In terms of field of study, midwifery students show higher level of anxiety, followed by nursery students and the lowest level of anxiety is reported by social work students.

\section{A. Recommendations}

Different activities and seminars should be organized by the universities for students suffering from anxiety and other psychological consequences related to Covid-19 pandemic. On the other hand students need to replace the time spent reading, watching or listening to news stories about COVID-19 with healthy activities like practicing yoga, exercising, meditation, joining some team sports, etc. Psychologists need to promote programs and services on treating psychological problems during the pandemic; this can encourage skeptical and shy students to seek professional help.

\section{ACKNOWLEDGMENT}

The researchers express their gratitude to the student of University of Shkoder who participated in this study.

\section{FUNDING}

The authors received no financial support for the research, authorship, and/or publication of this article.

\section{CONFLICT OF INTEREST}

No potential conflict of interest was reported by the authors.

\section{REFERENCES}

Adwas, A.A., Jbireal, J.M, Azab, E.A. (2019). Anxiety: Insights into Signs, Symptoms, Etiology, Pathophysiology, and Treatment. Kenya: East African Scholars Publisher.

Ahmed, O.,Faisal, R.A.,Sharker, T.,Lee, S.A., Jobe, M.C. Adaptation of the Bangla Version of the COVID-19 Anxiety Scale. International Journal of Mental Health Addiction. 2020, 1-12. https://doi.org/10.1007/s11469-020-00357-2.

Al Salman, ZH., Al Debel, F.A, Al Zakaria, F.A., Shafey, M.M., Darwish, M.A. (2020). Anxiety and depression and their relation to the use of electronic devices among secondary school students in Al-Khobar, Saudi Arabia. Journal of Family and Community Medicine, 27, 53-61. doi:10.4103/2230-8229.285820.

Alipour, A., Ghadami, A., Farsham, A., Dorri, N. (2020). A New Self-Reported Assessment Measure for COVID-19 Anxiety Scale (CDAS) in Iran: A Web-Based Study [Ref. Link].

Bialek, S., Boundy, E., Bowen, V., Chow, N., Cohn, A., Dowling, N., et al. (2020). Severe outcomes among patients with coronavirus disease 2019 (COVID-19) — United States, February 12-March 16, 2020. MMWR. Morbidity and Mortality Weekly Report, 69(12), 343-346

González-Sanguino, C., Ausín, B., Castellanos, M.Á., Saiz, J., López-Gómez, A., Ugidos, C., Muñoz, M. (2020). Mental health consequences during the initial stage of the 2020 Coronavirus pandemic (COVID-19) in Spain. Brain, Behavior, and Immunity, $87,172$.

Hasmujaj, E. (2021). Anxiety level of university students during covid-19 in department of Psychology and Social Work, Shkoder. https://oik-ks.org/wp-content/uploads/2021/06/Proceeding.pdf.

Huang, Y., \& Zhao, N. (2020). Generalized anxiety disorder, depressive symptoms and sleep quality during COVID-19 outbreak in China: A web-based cross-sectional survey. Psychiatry Research, 288, 112954 [Ref. Link].

Kef, K. (2021). COVID-19: The Level of Knowledge, Anxiety and Symptom Presentation. Psychol Res Behav Manag, 14, 541-548. doi: 10.2147/PRBM.S307050.

Kibbey, M.M., Fedorenko, E.J., Farris, S.G. (2021). Anxiety, depression, and health anxiety in undergraduate students living in initial US outbreak "hotspot" during COVID-19 pandemic. Cogn Behav Ther., 50(5), 409-421. https://doi.org/10.1080/16506073.2020.1853805.

Lai, J., Ma, S., Wang, Y., Cai, Z., Hu, J., Wei, N., et al. (2020). Factors associated with mental health outcomes among health care workers exposed to coronavirus disease 2019. JAMA Network Open, 3(3), e203976.

https://doi.org/10.1001/jamanetworkopen.2020.3976.

Lee, S. A. (2020). Coronavirus anxiety scale: A brief mental health screener for COVID-19 related anxiety. Death Studies, 44(7), 393-401. https://doi.org/10.1080/07481187.2020.1748481. 
Lei, L., Huang, X., Zhang, S., Yang, J., Yang, L., Xu, M. (2020). Comparison of Prevalence and Associated Factors of Anxiety and Depression Among People Affected by versus People Unaffected by Quarantine During the COVID-19 Epidemic in Southwestern China. Medical science monitor: international medical journal of experimental and clinical research, 26, e924609. https://doi.org/10.12659/MSM.924609.

Malesza, M., \& Kaczmarek, C.K. (2020). Predictors of anxiety during the COVID-19 pandemic in Poland. Pers Individ Dif, 170. doi: 10.1016/j.paid.2020.110419.

Mazza, C., Ricci, E., Biondi, S., Colasanti, M., Ferracuti, S., Napoli, C., Roma, P. (2020). A nationwide survey of psychological distress among Italian people during the COVID-19 pandemic: Immediate psychological responses and associated factors. International Journal of Environmental Research and Public Health, 17(9), 3165. https://doi.org/10.3390/ijerph17093165.

Rajkumar, R. P. (2020). COVID-19 and mental health: A review of the existing literature. Asian Journal of Psychiatry, 52, 102066. https://doi.org/10.1016/j.ajp.2020.102066.

Savitsky, B., Findling, Y., Ereli, A., Hendel, T. (2020). Anxiety and coping strategies among nursing students during the COVID-19 pandemic. Nurse Educ Pract., 46: 102809.

Shah, S.M.A., Mohammad, D., Qureshi, M.F.H. et al. (2021). Prevalence, Psychological Responses and Associated Correlates of Depression, Anxiety and Stress in a Global Population, During the Coronavirus Disease (COVID-19) Pandemic. Community Mental Health Journal, 57, 101-110.

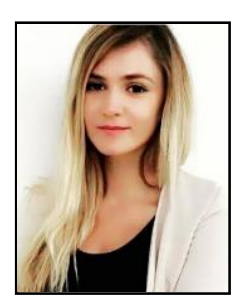

Elona Hasmujaj was born on 5 February 1986 in Shkoder, Albania. She graduated from the University of Shkoder with a Bachelor's degree in Psychology in 2007. After two years, in 2009, she graduated from the University of Florence, Italy, in Clinical and Community Psychology. She received her Scientific Master's degree in Clinical Psychology in 2011 and her Ph.D. degree in Psychology in 2017 from the Faculty of Social Sciences in Tirana, Albania.

She has more than 10 years experience as a psychologist, working in clinical and legal environment with individuals and family, involved in psychological assessment, investigation and treatment. From 2011 to the present, she has worked as a lecturer at the University of Shkoder and the University of Tirana, Albania, teaching Social Psychology, Communicative Psychology, Psychotherapy, Psychodiagnostics, Methods of Research in Psychology and Ethical Issues in Psychology. She has wide research experience in clinical psychology, cyberpsychology, developmental psychology, human relationships, forensic psychology, etc. She published about 40 manuscripts, of which $60 \%$ have been published in international journals.

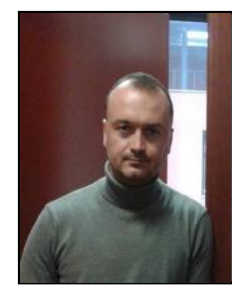

Albania.
Visar Dizdari was born on 26 July 1977 in Shkoder, Albania. He has a Bachelor's degree in Sociology from the University of Tirana (2000) and holds a Ph.D. in Methodology of Social Sciences from the Department of Political and Social Sciences, University of Florence (2014). He is a full-time lecturer of Sociology and Social Research at the University of Shkoder "Luigj Gurakuqi" (Albania), and from 2016 Head of Psychology and Social Work Department.

His main areas of interest and expertise include social research methodology, theoretical sociology, social problems, and social policy.

He has recently contributed to different books on issues related to social policies and social services in 